American Journal of Environmental Sciences 5 (1): 7-15, 2009

ISSN $1553-345 \mathrm{X}$

(C) 2009 Science Publications

\title{
The Role of Pioneer Vegetations in Accelerating The Process of Natural Succession
}

\author{
${ }^{1}$ Normaniza Osman, ${ }^{2}$ Faisal Haji Ali and ${ }^{1}$ Syed Shahar Barakbah \\ ${ }^{1}$ Institute of Biological Sciences, University of Malaya, 50603 Kuala Lumpur, Malaysia \\ ${ }^{2}$ Department of Civil Engineering, University of Malaya, 50603 Kuala Lumpur, Malaysia
}

\begin{abstract}
Problem Statement: Even though bioengineering technique has been regarded as one way to alleviate landslide and erosion problems, this process of revegetation is severely time consuming as the process of plant succession of the slopes may take decades or even hundreds of years. Approach: However, the process can be tremendously hastened by planting the right suitable pioneer species on the slopes. In this project, a natural succession experiment was conducted to determine the role of a potential slope colonizer, L. leucocephala, as a good pioneer in two years of observation. Results: In terms of the plant community, L. leucocephala had tremendously accelerated the plant succession of the slope. Within two years, 46 species comprising various species of grasses, shrubs and small trees colonized in the mixed culture treatment. The plant diversity increased drastically, about five (12 months) and eight fold (24 months) of its initial (0 month) diversity against 2.5 (12 months) and three fold (24 months) in the monoculture treatment. Related to this species-richness, LAI and biomass of the plant community was also enhanced in the mix-culture system. Conclusion: The results indicate that the species studied exhibits an outstanding pioneering characteristic by enhancing natural succession and the revegetation process which will be in turn, resulting in a more stable ecosystem.
\end{abstract}

Key words: natural succession; pioneer; mixed culture; monoculture; species diversity

\section{INTRODUCTION}

For centuries, wood and living plants were used as materials for hills and slope stabilization works. Today, some of these conventional techniques have been modified and reapplied due to the increasing failures of traditional methods and practices. What was thought successful in the past is being re-evaluated in the context of the impacts resulting from excessive and rapid urbanization and public awareness of these timesensitive environmental issues. The revegetation process, for instance, has to be hastened to avoid further damage to environment, properties and more importantly, life. In order to achieve this purpose, the right propagation density and suitable plant type are, inter alia, critical. Amongst the plant type used, the introduction of the suitable pioneer species is crucial. For example, whether it accelerates the process of natural succession requires objective assessment.

Natural plant succession develops from initial pioneer vegetation. As such, the choice of plant is critical, as this pioneer must have several good characteristics. These include fast growing capacity, nitrogen fixing, self-sustainability, good plant water relations and extensive root system. The pioneer vegetation must be able to rapidly convert infertile soil into a habitat suitable for vegetation. Thus, a leguminous tree is a good choice as a pioneer as it has the ability to enrich sterile soils. It fertilizes soil by fixing nitrogen where soils are deficient in nutrients.

Amongst the tree legumes, Leucaena leucocephala (Lam.) de Wit has been determined as one of the versatile pioneer ${ }^{[1]}$. This bushy, evergreen leguminous tree can reach a height of $30 \mathrm{ft}$. upon maturity. It is widespread throughout the tropics and is abundant in villages in the northern part of Malaysia. It is a multipurpose tree which profusely produces propagules (beans) and has been used as an erosion control plant ${ }^{[2]}$. L. leucocephala is chosen in this study based on these reports coupled with the fact that there is a woeful lack of documentation on its contribution to ecological conservation.

Having successfully gone through a series of plant screening, including an outstanding root reinforcement capacity via its extensive root profile $\mathrm{e}^{[3]}$, L. leucocephala was assessed on the newly cut slope. The capability of $L$. leucocephala in enhancing the process of natural succession and eventually producing a sustainable

Corresponding Author: Normaniza Osman, Institute of Biological Sciences, University of Malaya, 50603 Kuala Lumpur, Malaysia 
ecosystem on the slope was evaluated. Does L. leucocephala pave the way for other successors? Or, does it suppress the growth of other plants? In order to answer these curiosities, the gross performance of L. leuccoephala along with the plant community was assessed in terms of the development of Leaf Area Index (LAI), biomass and plant diversity.

\section{MATERIALS AND METHODS}

Plant materials: L. leucocephala seedlings were obtained from Rubber Research Institute of Malaysia and grown in an open-ended PVC pipe (Fig. 1). The seedlings were transferred to the slope after reaching a height of $1.0 \pm 0.1 \mathrm{~m}$ (about two months after germination). Concurrently, four other species were also grown in PVC pipes until they reached about a similar height to L. leucocephala. These species, namely Justicia betonica, Tabernaemontana corymbosa, Polycias sp. and Evodia latifolia, were chosen based on the prominent criteria as slope plants in previous pilot trials ${ }^{[4]}$.

Natural succession experiment: The experiment was carried out in four treatments. Four treatment plots $\left(1800 \mathrm{ft}^{2} /\right.$ plot $)$ of the same soil condition and soil type were bioengineered on a barren slope at Rimba Ilmu (124 m altitude, longitude E $101^{\circ} 39^{\prime}$ 25.9', latitude N $\left.03^{\circ} 07^{\prime} 51^{\prime \prime}\right)$, University of Malaya. The treatments were G (grass only), LL (planted with L. leucocephala only), SS (planted with four shrubs species) and LLSS (planted with L. leucocephala and four shrubs species). The creeper, Pueraria phaseoloides, was sown in all plots at 1100 seeds per metre length (germination rate was $30 \%$ ) to improve the quality of the barren soil.

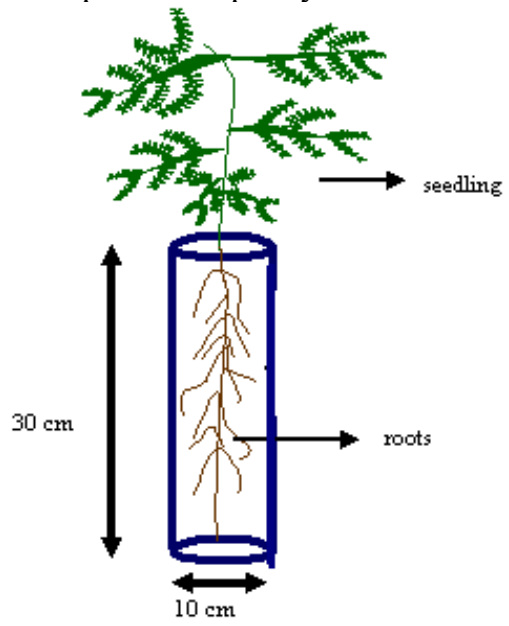

Fig. 1: Planting technique. Seedling is grown in an open-ended customized PVC tube for two months $(\sim 1.0 \mathrm{~m}$ in height $)$
When Pueraria phaseoloides had established on the slope (about three weeks), L. leucocephala and the other plant species, in five replications, were transferred into the respective plots. All plants were planted in a Complete Randomized Design (CRD). The details of the plots are summarized and tabulated (Table 1). Physiological aspects of L. leucocephala, performance of the plant community and contribution of the species studied in enhancing natural succession and hence slope stability was assessed throughout the two-year experimental period.

In the beginning of experiment, all plots (except $\mathrm{G}$ plot) had the same number of plants i.e., 25. The schematic design of the showcase slope is sketched (Fig. 2a and b).

Measurements: Gross parameters: photosynthetic rate, stomatal conductance and Leaf Area Index (LAI): Photosynthetic rate was measured using the Portable Photosynthetic System (PPSystem, CIRAS-1, USA).

\begin{tabular}{|c|c|c|}
\hline Plot & Type & Species \\
\hline G & $\begin{array}{l}\text { Monoculture } \\
\text { (grass only) }\end{array}$ & $\begin{array}{l}\text { Ischaemum muticum (grass)-already grown } \\
\text { on slope Pueraria phasoiloides (creeper) }\end{array}$ \\
\hline LL & $\begin{array}{l}\text { Grass and } \\
\text { Leucaena } \\
\text { leucocephala }\end{array}$ & $\begin{array}{l}\text { Ischaemum muticum Pueraria phasoiloides } \\
\text { (creeper) Leucaena leucocephala (LL) }\end{array}$ \\
\hline SS & $\begin{array}{l}\text { Mix-culture } \\
\text { (without Leucaena } \\
\text { leucocephala) }\end{array}$ & $\begin{array}{l}\text { Ischaemum muticum (grass) Pueraria } \\
\text { phasoiloides (creeper) Justicia betonica } \\
\text { Tabernaemontana corymbosa Polycias } \mathrm{sp} . \\
\text { Evodia latifolia }\end{array}$ \\
\hline LLSS & $\begin{array}{l}\text { Mix-culture } \\
\text { (with Leucaena } \\
\text { leucocephala) }\end{array}$ & $\begin{array}{l}\text { Ischaemum muticum (grass) Pueraria phasoiloides } \\
\text { (creeper) Leucaena leucocephala (LL) } \\
\text { Justicia betonica Tabernaemontana corymbosa } \\
\text { Polycias } \text { sp. Evodia latifolia }\end{array}$ \\
\hline
\end{tabular}

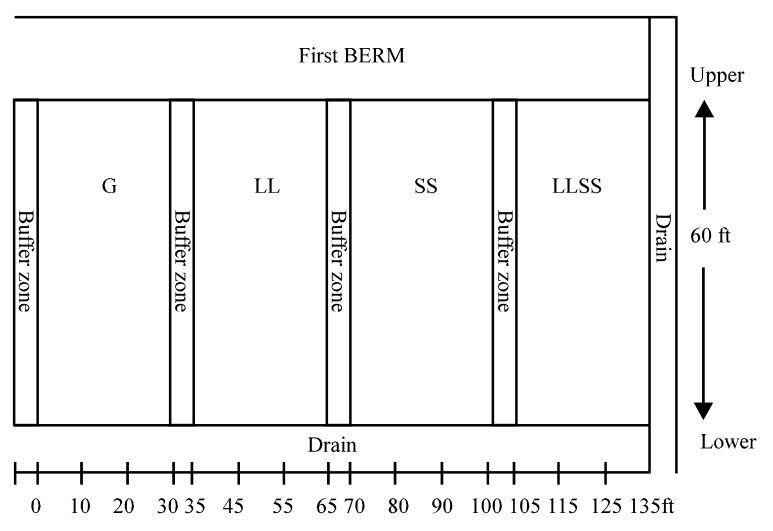

Fig. 2a: Four treatments on a showcase slope, Rimba Ilmu, University of Malaya $(\mathrm{G}=$ grass only, $\mathrm{SS}=$ shrubs, $\mathrm{LL}=L$. leucocephala only and LLSS $=$ L. leucocephala and shrubs) 


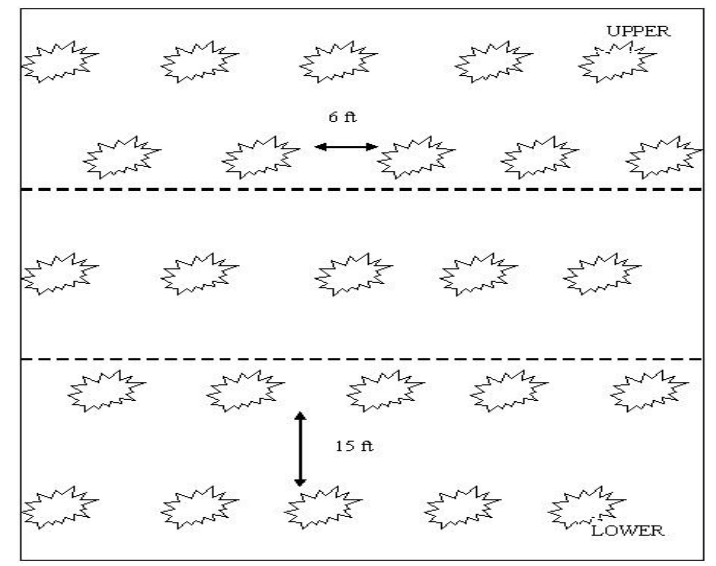

Fig. 2b: A schematic design of mix-culture plots (SS and LLSS). All plant species were planted in a complete randomized design in these plots. The monoculture (LL plot) was laid-out in the similar design to the mix-culture. Only L. leucocephala was grown in LL plot. The dashed line represents $P$. phaseoloides (legume cover).

Stomatal conductance was measured by a transient time portable porometer (Delta T Devices, model AP4, UK) and the measurements were taken between 1200-1400 hours with PAR at $1800-2100 \mu \mathrm{E} \mathrm{m}^{-2} \mathrm{~s}^{-1}$. These two measurements of photosynthetic rate and stomatal conductance were measured randomly on the six youngest fully expanded leaves, taken once, at 18month of growth. Leaf area index (LAI) was measured randomly (five replicates) using the plant canopy analyzer (LICOR, model LAI-2000, USA), after 12 and 24 months of growing duration.

In order to determine the growth rate, photosynthesis was measured diurnally at the end of experiment (24 months). The growth rate of L. leucocephala was determined by the following formula:

$$
\begin{aligned}
& \text { Growth rate }\left(\text { g plant }^{-1} \text { day }^{-1}\right)=(A \times C \times L \times t)- \\
& \qquad\left(R_{N} \times C \times L \times t\right)=C \times L \times t\left(A-R_{N}\right)
\end{aligned}
$$

Where:

$$
\begin{aligned}
& \mathrm{A}=\text { Net photosynthetic rate }\left(\mu \mathrm{mol} \mathrm{m} \mathrm{m}^{-2} \mathrm{sec}^{-1}\right) \\
& \mathrm{R}_{\mathrm{N}}=\text { Night respiration }\left(\mu \mathrm{mol} \mathrm{m}^{-2} \mathrm{sec}^{-1}\right) \\
& \mathrm{C}=\text { Molecular weight of } \mathrm{CO}_{2}(44) \\
& \mathrm{L}=\text { Leaf Area Index }\left(\mathrm{m}^{2}\right) \\
& \mathrm{t}=\text { Time (day length }=\text { Night length }=12 \mathrm{~h})
\end{aligned}
$$

Species diversity: Quadrates $(1 \times 1 \mathrm{~m})$ were used to determine the plant diversity and biomass which were measured diagonally across each plot. For plant sampling (quadrates), the method of Austin ${ }^{[5]}$ was used. Plant samplings were taken from the permanent plot with three random subsamples through time. The relative frequency of each species was determined as follows: [frequency of one species $/ \Sigma$ frequency of all species $] \times 100 \%$. The species diversity was determined at $0,6,12,18$ and 24 months of growth that is every six months throughout the two-year treatment.

Dry weight partitioning and biomass: Biomass of stem, leaf and root were obtained twice, at 12 and 24 months of growth. All parts were oven-dried $\left(80^{\circ} \mathrm{C}\right)$ to constant weight.

Statistical analysis: Statistical analysis was performed using STATGRAPHIC Plus 3.0. The one way ANOVA was applied to evaluate the significant difference of the parameters studied in the five different soil treatments (one factor). LSD $(p=0.05)$ was calculated using the error mean squares of the analysis of variance. The correlation test between the parameters studied was analyzed using Microsoft Excel.

\section{RESULTS}

Physiological Performance of L. leucocephala: The increment of LAI was about 87 and $60 \%$ higher in LLSS treatment than that of LL, in 12 and 24 months, respectively (Fig. 3). This implies that $L$. leucocephala is induced to grow better when there is competition with other species in terms of nutrient or water. Apart from that, the results (Fig. 4) also showed that the treatments affect photosynthetic rate (A) and stomatal conductance $\left(\mathrm{g}_{\mathrm{s}}\right)$. This was shown by a highly significant difference between LLSS and LL treatments. Both parameters of L. leucocephala in the LLSS plot were $68 \%(\mathrm{~A})$ and $153 \%\left(\mathrm{~g}_{\mathrm{s}}\right)$ higher than that of in the LL. The results imply that L. leucocephala grew and adapted well on slope in the mix-culture system.

Growth rate: Results showed that the growth rate of L. leucocephala was higher in LLSS than in LL plot. The growth rate was 70.2 and $27.6 \mathrm{~g} \mathrm{plant}^{-1}$ day $^{-1}$, respectively (Fig. 5). The faster growth rate observed in LLSS treatment is presumably attributed to the high competition amongst the species in terms of light, space, nutrient and water. The species studied seems to enhance inherent resources use efficiency when competing with other species. Therefore, the photosynthetic activity and hence, the development of leaf area were enhanced. This result also reflects the 
Am. J. Environ. Sci., 5 (1): 7-15, 2009

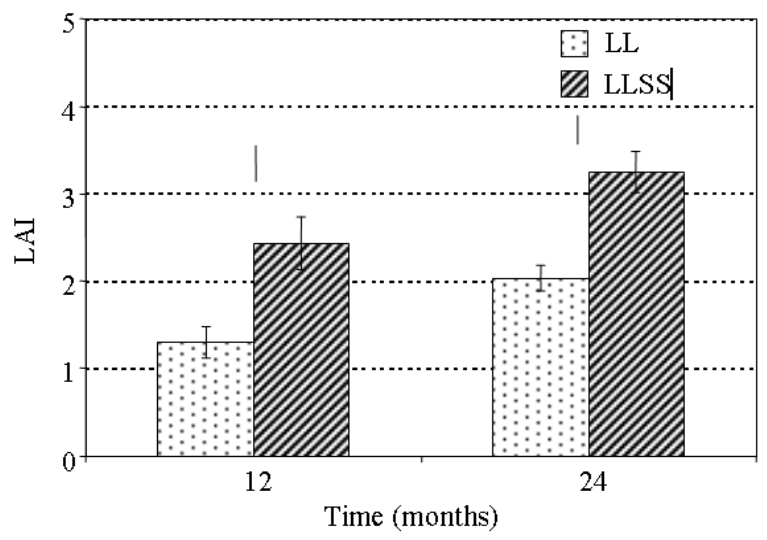

Fig. 3: LAI of L. leucocephala in LL and LLSS plots. Vertical bars represent standard deviation and vertical lines represent LSD $\mathrm{p}<0.05$

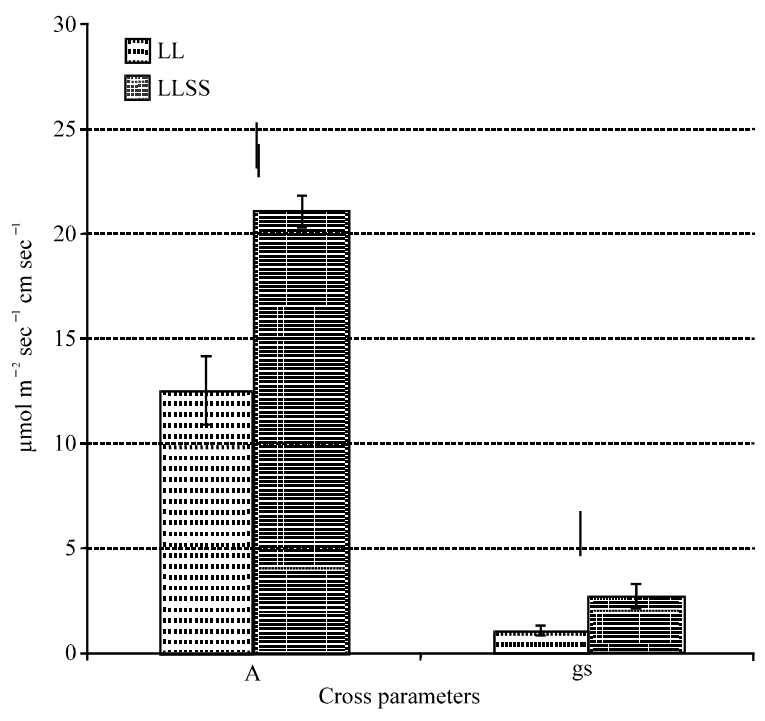

Fig. 4: Gross parameters of L. leucocephala in LL and LLSS plots at 18 months. Vertical bars represent standard deviation and vertical lines represent LSD $\mathrm{p}<0.05$

high level of carbon sink of species studied in the mixculture system. In perspective, the comparison in growth rate is assessed between L. leucocephala and other potential slope trees (Table 2). The growth rate of L. leucocephala is observed to be the highest amongst the plants, followed by Evodia latifolia (54.4 $\mathrm{g} \mathrm{plant}^{-1}$ day $^{-1}$ ) and Switenia mahogany $\left(53.3 \mathrm{~g} \mathrm{plant}^{-1}\right.$ day $\left.^{-1}\right)$. The fastest growth rate shows a remarkable characteristic of $L$. leucocephala, essential for slope colonizer. A faster growing plant can contribute to reduce initial surface erosion via acting as a barrier e.g., enhance rainfall interception and decrease velocity of rainfall.
Table 2: Growth rate of L. leucocephala and other potential slope plants (using the same experimental protocol and calculation)

\begin{tabular}{lll}
\hline Species & $\begin{array}{l}\text { Growth rate } \\
\left(\mathrm{g}^{-1} \text { plant }^{-1} \text { day }^{-1}\right)\end{array}$ & Rank \\
\hline Leucaena leucocephala & 70.2 & 1 \\
Switenia mahagony & 53.3 & 3 \\
Evodia latifolia $^{1}$ & 54.4 & 2 \\
Tectonia grandis $^{1}$ & 41.1 & 5 \\
Hopea orodata $^{1}$ & 51.4 & 4 \\
\hline
\end{tabular}

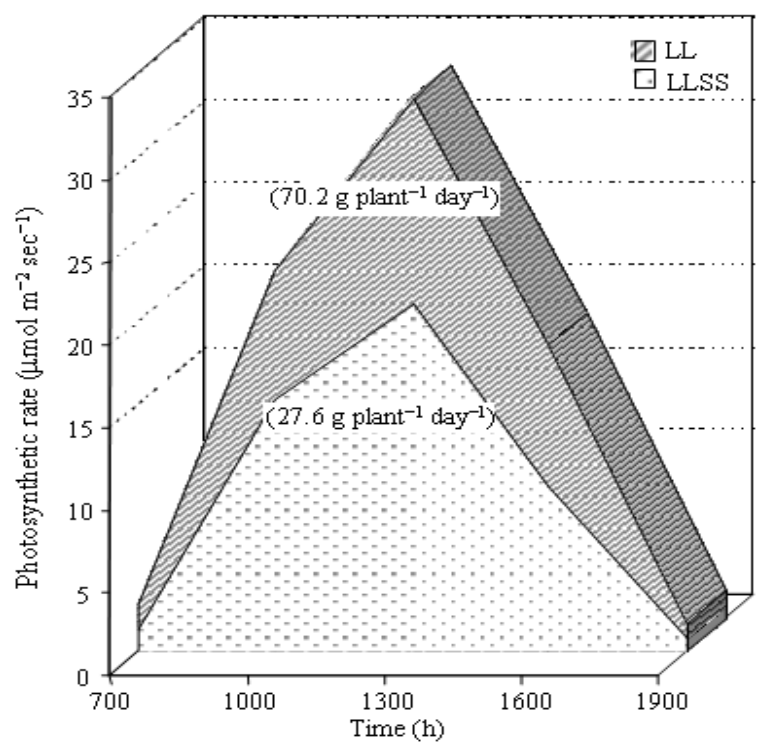

Fig. 5: Diurnal photosynthetic rate of $L$. leucocephala in LL and LLSS plots (value of growth was indicated within bracket)

Performance of plant community: Species Diversity (6, 12, 18 and 24 months): Species diversity was analyzed only in LL and LLSS plots in order to see the effect of monoculture and mix-culture treatments on the performance of $L$. leucocephala as a pioneer. After 24 months of growth, 46 plant species had established in the LLSS plot, consisting of different species of grasses, shrubs, ferns and medium size trees. The plot showed steady enhancement of biomass and was in fact fully covered by diverse species in 12 months (Fig. 6). Species composition and life form diversity of the plant communities changed rapidly in the LLSS plot. The results showed that species diversity of the mix-culture system increased tremendously, by five fold of the initial number of species after 12 months of observation (Fig. 7). The results imply that in this system, L. leucocephala and other planted shrubs has a positive role in increasing plant diversity. The color and nectar of the flowers (of shrubs) and the young green pods (L. leucocephala) attract insects and birds into the 
ecosystem. In addition, these insects and birds are also the agent of dispersal because they carry seeds from other places into this plot. Thus, this flora-fauna interaction also allows the influx of other species and consequently increases in biodiversity. In contrast, only six species was observed in the LL plot at the end of experiment (24 months). A lack of flora-fauna interaction may lead to low plant diversity. The rate of succession is also low compared to LLSS plot. This can be observed in a high percentage of barren soil (about $40 \%$ of ground cover) even after 12 months of observation (Fig. 6). In fact, there was a sign of eroding soil in November 2000 (after 12 month observation). This presumably is due to the high intensity rainfall, about $550 \mathrm{~mm}$, which was also the peak of the year. Furthermore, some species e.g. Ischaemum muticum (grass) and Axonopus compressus (grass) in the plot faded away and caused barren almost $30 \%$ of the ground cover, resulting in low sustainability and stability of the plot (24 months). The plant diversity in LLSS plot increased by more than double ( 6 and 12 months) and even triple (24 months) that of the LL (Fig. 5). This indicates that $L$. leucocephala performs better in the mix-culture system in accelerating the process of natural succession.

Performance of pioneer species: The percentage of ground cover and frequency of $L$. leucocephala gradually increased in both LL and LLSS (Fig. 8a and d). This implies that $L$. leucocephala has vigorously grown in both plots. This observation may be attributed to the presence of $L$. leucocephala seedlings at both plots, indicating the plant is easily-grown and has high growth rate. The results also indicate that the plant studied can withstand the high competition amongst the adverse species in the LLSS plot without influencing its growth. This has been proven by a significantly high LAI of the species studied at the end of the observation (Fig. 3). In terms of relative frequency, L. leucocephala in the LLSS treatment exhibited a higher value than those in the LL throughout the observation (Fig. 8d). More seedlings were also observed in the LLSS plot.

The legume cover crop, P. phaseoiloides, which was sown along with $L$. leucocephala in both experimental plots, vigorously grew in the LLSS plot at the beginning of the trial (6 months) but its relative ground cover and frequency decreased with time (Fig. $8 \mathrm{~b}$ and e). Apparently, the legumes faded in both plots and were replaced by other species. The legumes ultimately decreased by $91.6 \%$ and $27.3 \%$ in both LLSS and LL treatments, respectively. A similar trend was observed in the grass species, I. muticum (already in existence on the slopes in both trials). In both treatments, the grass showed high increments in both ground cover and frequency, especially in the LL plot, but only up to six months of observation. Both parameters gradually decreased beyond that period, presumably due to the shading effect from the canopy of the tree species (Fig. 8c and f).

Performance of dominant successors: Amongst the established successors, Melastoma malabathricum had consistently persisted in almost all plots during and beyond the six months of observation. This species occupied $4-15 \%$ of ground cover at the end of the observation (Fig. 9a and d). The result suggests that this species appears to be the best invader of the slopes. Another dominant species observed was Axonopus compressus (grass species), showing an increment in the relative frequency and ground cover in the LL plot

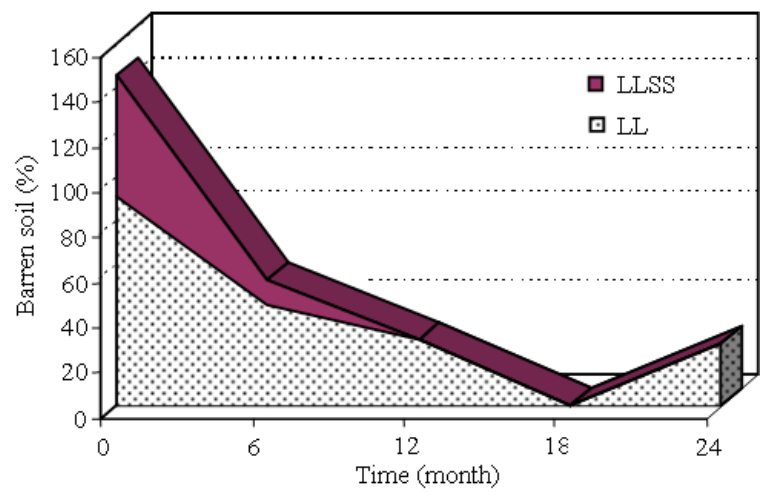

Fig. 6: Percentage of barren soil in LL and LLSS plots

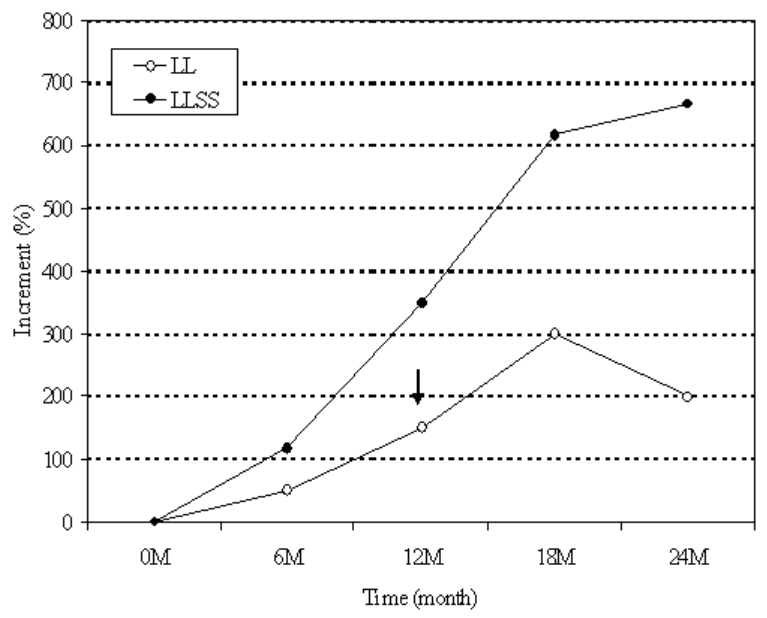

Fig. 7: Percentage of diversity increment in LL and LLSS plots (arrow shows the time of soil erosion in the LL treatment) 


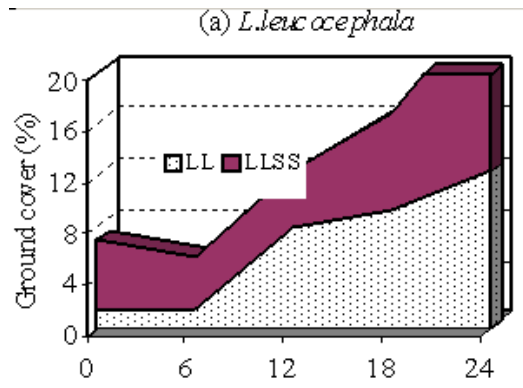

(d) L.leucocephala

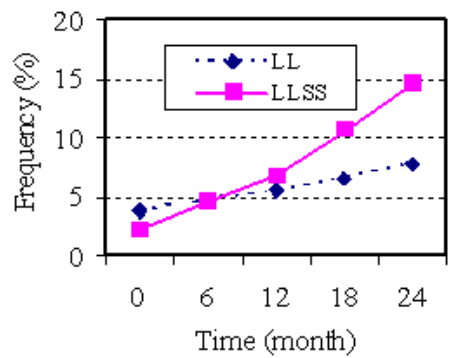

(b) Pphoseoiloides

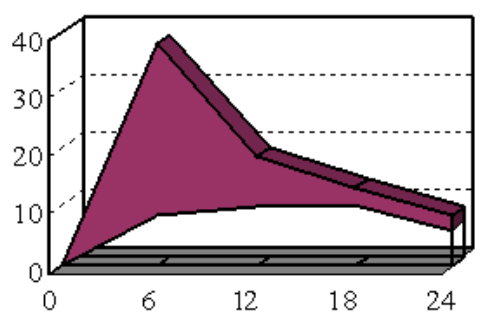

(e) P.phaseoiloides

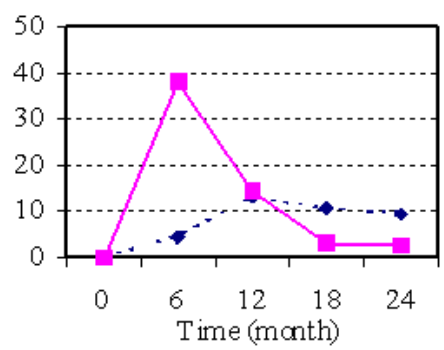

(c) Imuticum (grass)

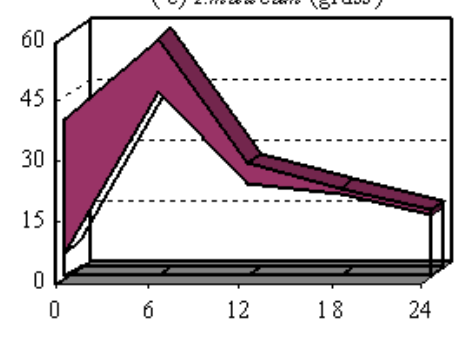

(f) I.mutioum (grass)

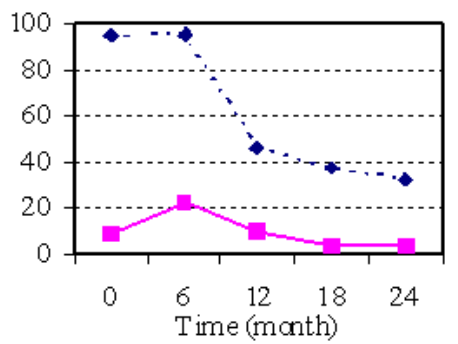

Fig. 8: Percentage of ground cover and frequency of pioneer species
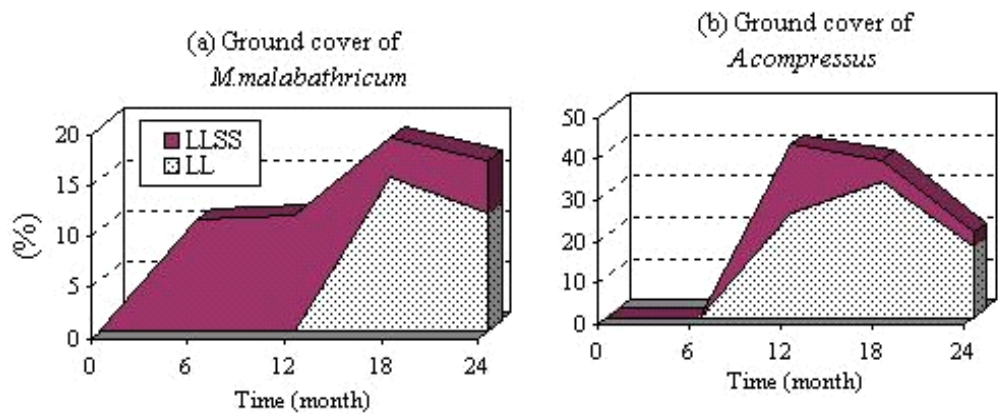

(c) Frequency and ground cover of Sindica (in LLSS)

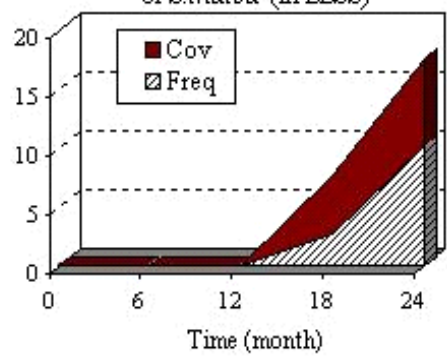

(d) Frequency of
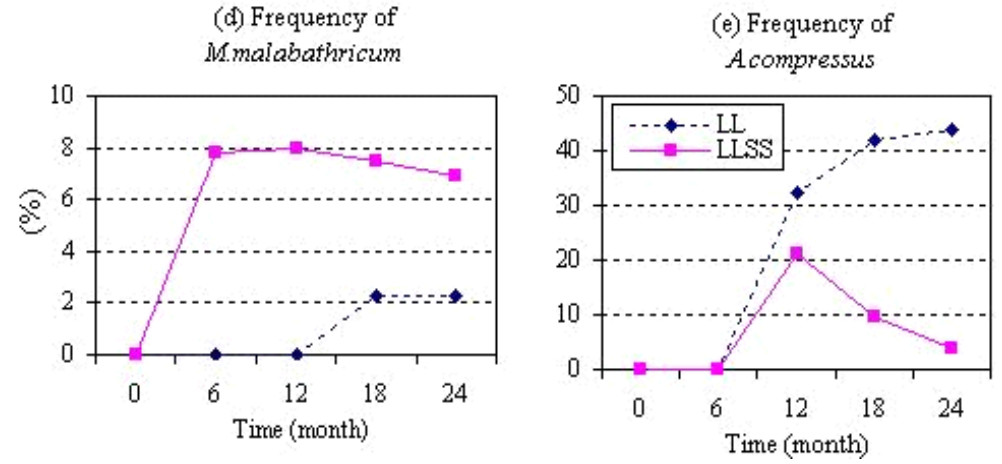

(f) Frequency and ground cover of D.lineansis (in LLSS)

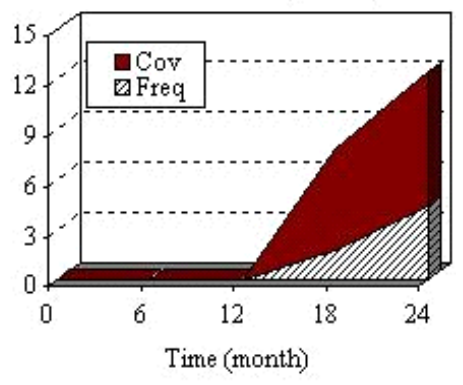

Fig. 9: Dominant successors in either both plots or only in the LLSS plot

(Fig. 9b and e). Stachytarpheta indica (shrubs) and Dicranopteris linearis (fern species) were established after six and twelve months of trials, respectively
(Fig. 9c and f). The frequency and ground cover of these species rapidly increased beyond the one-year observation (Fig. 9c and f). 
Leaf area index: The results showed that there was a considerable increase of LAI between 12 and 24 months in all treatments (Fig. 10). The value increased by 76, 19, 27 and $44 \%$ in G, LL, SS and LLSS plots, respectively. Although G plot exhibited the highest increment amongst the plots, its LAI value was the lowest in both 12 and 24 months of observation. The highest increment in G plot is a fallacy because the initial value was very low. The results imply that there was little plant succession and establishment of new seedlings in the plot. Even if there was seed dispersal into this plot, the probability of germination was low due to high surface runoff.

The influence of the mix-culture treatments (LLSS and SS) clearly shows that L. leucocephala enhances the LAI in a plant community. LAI value had also significantly increased with the presence of L. leucocephala in the mix-culture plot (LLSS), which was almost double that of the SS (without L. leucocephala).

These results suggest that the mixed culture model that is integrated with L. leucocephala would result in higher development of LAI. The observation is possibly attributed to the high photosynthetic activity and growth.

Leaf area index: The results showed that there was a considerable increase of LAI between 12 and 24 months in all treatments (Fig. 10). The value increased by 76, 19, 27 and $44 \%$ in G, LL, SS and LLSS plots, respectively. Although G plot exhibited the highest increment amongst the plots, its LAI value was the lowest in both 12 and 24 months of observation.

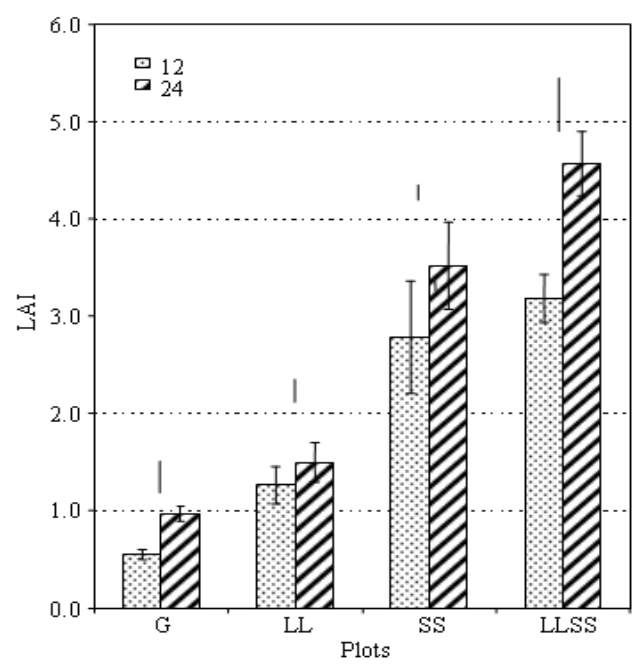

Fig. 10: LAI in four different plots after 12 and 24 months. Vertical bars represent standard deviation and vertical lines represent LSD $\mathrm{p}<0.05$
The highest increment in G plot is a fallacy because the initial value was very low. The results imply that there was little plant succession and establishment of new seedlings in the plot. Even if there was seed dispersal into this plot, the probability of germination was low due to high surface runoff.

The influence of the mix-culture treatments (LLSS and SS) clearly shows that L. leucocephala enhances the LAI in a plant community. LAI value had also significantly increased with the presence of L. leucocephala in the mix-culture plot (LLSS), which was almost double that of the SS (without L. leucocephala). These results suggest that the mixed culture model that is integrated with L. leucocephala would result in higher development of LAI. The observation is possibly attributed to the high photosynthetic activity and growth rate of the diverse species, which resulted in a greater competition for light and subsequently accelerated growth of the whole plant community.

Biomass: The highest percentage of increment (between 12 and 24 months) in biomass was observed in LLSS (112\%), followed by LL (74\%) and SS (47\%) (Fig. 11). No significant difference was observed in $\mathrm{G}$ plot. The results also imply that the mix-culture system with L. leucocephala (LLSS) had greater biomass compared to the mix-culture system without $L$. leucocephala (SS). This portrays a positive role of $L$. leucocephala in accelerating stable ecosystem through the enhancement in biomass.

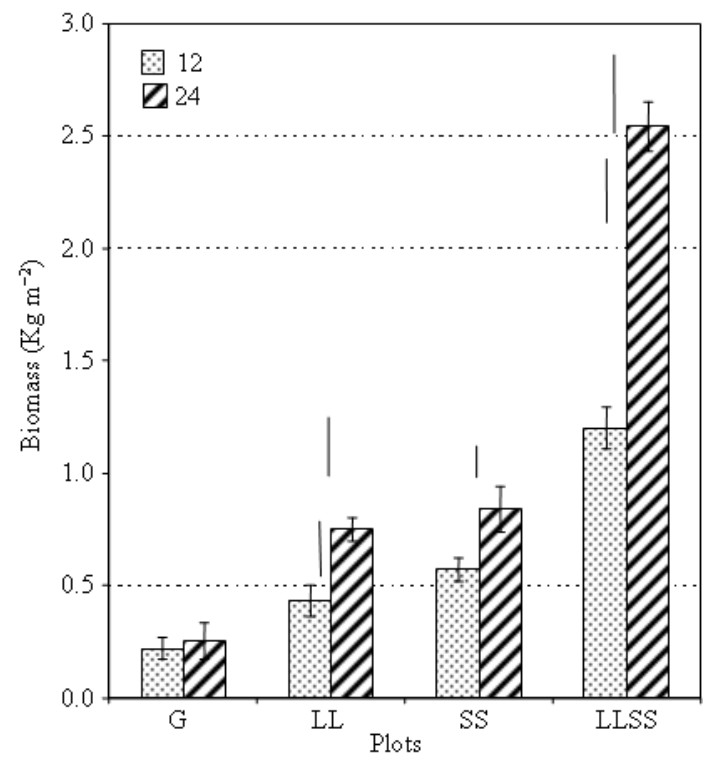

Fig. 11: Biomass in four different plots after 12 and 24 months. Vertical bars represent standard deviation and vertical lines represent LSD $\mathrm{p}<0.05$ 
Am. J. Environ. Sci., 5 (1): 7-15, 2009

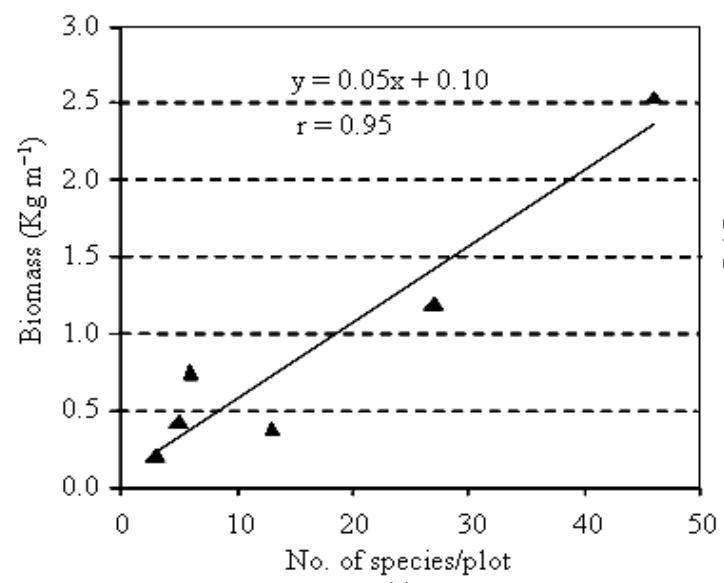

(a)

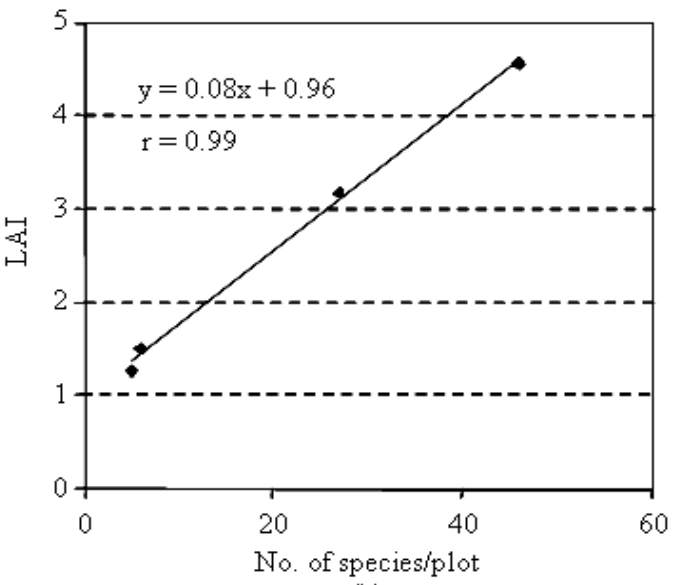

(b)

Fig. 12: Relationship amongst the gross parameter studied. (a): Bomass and plant diversity, (b): LAI and plant diversity

In addition, in the task of enhancing the process of plant succession and vegetation establishment on slope (succession management), biomass could not be enhanced by planting merely grasses (as in G plot). Succession management is more likely to be beneficial when mixed culture is practiced, especially involving $L$. leucocephala. The results also showed that there was a significant increase in biomass between 1224 months in both LL and LLSS treatments. The LLSS also showed higher biomass by $180 \%$ (12 months) and $340 \%$ (24 months) than those in the LL treatment, displaying the influence of mixed culture environment on biomass. The above observations may be attributed to high plant diversity and LAI observed in the LLSS plot. This postulation was tested by linear correlation amongst the parameters studied.

Biomass seems to strongly correlate with diversity $(\mathrm{r}=0.95$, Fig. 12a) and LAI $(r=0.99$, Fig. 12b) the observation also implies that plant biomass, density and diversity are important factors to consider in the task of slope stabilization, in coherence to the finding of Thorne $^{[6]}$. However, this result contrasted with the results of Tatoni and Roch ${ }^{[7]}$ who stated that species diversity decreased as LAI increased. The contrast may be attributed to a function of light interception which is low in L. leucocephala due to its leaf morphology. The species studied was also reported to have a prominent criterion in terms of shade tolerance as its leaf area and growth rate were not affected by shading ${ }^{[8]}$.

\section{DISCUSSION}

From visual observation, $L$. leucocephala successfully grew in the mix-culture system (LLSS).
The species studied is fast growing, an essential characteristic of a slope stabilizer. The plant successfully accelerated the process of natural succession via influx of other species. Species diversity had increased by 3.5 fold after six months of observation. Within two years, the vegetation dynamics of the LLSS plot at the slope of Rimba Ilmu, University of Malaya had markedly increased to 46 plant species, comprising grasses, shrubs and small trees. Other dominant successors observed were Melastoma malabathricum which covered up to $15.0 \%$ of ground cover, Stachytarpheta indica (shrubs) and Dieranopteris lineanis (fern). Axonopus compressus (grass) gradually decreased in the LLSS plot, implying a high competition with other species that suppressed its growth.

In this project, it is shown that a bioengineered slope is self-regenerating and sustainable ecosystem, once L. leucocephala was established, they modify the ecosystem through changes in plant biomass, soil and microclimate conditions. Its potential as a nitrogen fixer is reflected in its prominent growth in terms of LAI and biomass. In the subsequent successional phase, new species for example Melastoma malabathricum, Stachytarpheta indica and Dicranopteris linearis, whose optimum growth range fits these new set of conditions can be established and grown in a short period of time. In addition, the study also shows that $L$. leucocephala does exhibit an 'open vegetation' characteristic in which it allows the influx and growth of plant species. It sustains in the midst of high competition for space, nutrients, water and light in the plant community. Thus, the process of natural succession is enhanced with increasing biodiversity. 


\section{CONCLUSION}

The overall results have proven the ability of L. leucocephala alone, to exhibit good pioneer characteristics in terms of accelerating the process of natural succession of the slope via influx of other species. The species studied was competed well with other colonized species in the ecosystem. Furthermore, in the mix-culture system, the species was more successful in terms of plant physiological criteria such as, photosynthetic rate and stomatal conductance and fast growth rate and it is visualized that a well-grown ecosystem has been established within the two years of observation with the presence of L. leucocephala, either in LL (monoculture) or LLSS (mix-culture plots). It sustains in the midst of high competition for space, nutrients, water and light in the plant community. Thus, the process of natural succession is enhanced with increasing biodiversity. This, in return, enhances slope stability, lowering the risk of potential erosion and landslide especially in newly cut slopes.

\section{ACKNOWLEDGMENT}

The researchers would like to thank University of Malaya for the research grant throughout this project. The researchers are also grateful to PLUS Bhd. for the use of their equipment.

\section{REFERENCES}

1. Duke, J.A. and J.L.D. Cellier, 1993. CRC Handbook of Alternative Cash Crops. 1st Edn., CRC Press, Ann Arbor-London, ISBN: 10: 0849336201, pp: 294-296.
2. Parera, V., 1983. Leucaena for erosion control and green manure in Sikka. Proceedings of the meeting on Leucaena Research in the Asian-Pacific Region, Nov. 23-26, International Development Research Centre, Ottawa, Canada, pp: 169-173. https://idlbnc.idrc.ca/dspace/handle/123456789/21012.

3. Normaniza, O., H.A. Faisal and S.S. Barakbah, 2008. Engineering properties of Leucaena leucocephala for prevention of slope failure. Ecol. Eng., $\quad 32$ : 215-221. DOI: 10.1016/j.ecoleng.2007.11.004.

4. Normaniza, O. and S.S. Barakbah, 2006. Parameters to predict slope stability - soil water and root profiles. Ecol Eng., 28: 90-95. DOI: 10.1016/j.ecoleng.2006.04.004.

5. Austin, M.P., 1981. Permanent quadrats: On interface for theory and practice. Plant Ecol., 46: 1-10. DOI: 10.1007/BF00118379.

6. Thorne, C.R., 1990. Effects of Vegetation on Riverbank Erosion and Stability. In: Vegetation and Erosion: Processes and Environments. Thornes, J.B. (Ed.). John Wiley and Sons Ltd., England, pp: 125-136.

7. Tatoni, T. and P. Roche, 1994. Comparison of oldfield and forest revegetatin dynamics in Provence. J. Vegetat. Sci., 5: 295-302. http://www.fao.org/ agris/search/display.do?f=./1994/v2017/SE941126 2.xml;SE9411262.

8. Egara, K. and R.J. Jones, 1977. Effect of shading on the seedling growth at the leguminous shrub Leucaena leucocephala. Aus. J. Exp. Agric. Anim. Husband., 17: 976-981. Doi: 10.1071/EA9770976. 